\title{
AVALIAÇÃO FÍSICO-QUÍMICA DA FARINHA DE MANDIOCA PRODUZIDA EM DIFERENTES ESTADOS DO PAÍS.
}

\author{
L. de O. COSTA $^{1}$, L. BARROS ${ }^{2}$, M. M. de O. SILVA 3 .
}

${ }^{1 .}$ Graduanda pela Universidade Federal do Ceará, Departamento de Tecnologia de Alimentos. laiana.costa@hotmail.com

2. Professora Dra. na Universidade Federal do Ceará, Departamento de Tecnologia de Alimentos. lucicleiabarros@hotmail.com

${ }^{3}$ Graduada pela Universidade Estadual do Ceará - UECE. Laboratório de Bioquímica e Biotecnologia.marinamaciell@yahoo.com.br.

RESUMO - As farinhas de mandioca, do grupo d'água e seca, de diferentes Estados do Brasil, foram analisadas no laboratório de análises química da secretaria de desenvolvimento agrário do estado do Ceará. Visando à adequação do produto à legislação vigente foram realizadas as determinações de teor de umidade, cinzas, fibra bruta, acidez e amido. O valor máximo permitido pela Legislação para o teor de umidade é de $13 \%$, as amostra analisadas apresentaram resultados entre $5,41 \%$ e $11,22 \%$. Segundo a legislação o teor máximo de cinzas é de 1,4\%, estando os valores obtidos para as amostras entre $0,67 \%$ e $1,35 \%$. O teor de amido mínimo adotado pela legislação é de $70 \%$, os resultados variaram entre 84,97 e $93,79 \%$. Para a fibra bruta a legislação estipula valor máximo de $2,3 \%$, as amostras obtiveram valores bastante variáveis entre $2,21 \%$ e $0,29 \%$. Todas as variáveis analisadas destes produtos apresentaram resultados condizentes com a Legislação Brasileira, podendo estes, serem consumidos com segurança e qualidade.

\section{INTRODUÇÃO}

A mandioca (Manihot esculenta) desempenha um papel de alta importância econômica e social para muitos Estados do País, pois é considerada um dos produtos básicos da dieta alimentar da população brasileira. Há muitos séculos constitui o principal produto agrícola cultivado pelos indígenas e por grande parte da população rural. Na região Norte a produção de mandioca destinase principalmente à fabricação de farinha, produto considerado símbolo dessa cultura, gerando emprego e renda para milhares de famílias de agricultores (Silva \& Lima, 2012).

A definição de farinha, segundo a Legislação Brasileira, é o produto obtido pela moagem da parte comestível de vegetais, podendo sofrer previamente processos tecnológicos adequados, 
devendo o produto ser denominado de farinha seguido do nome do vegetal de origem. A farinha de mandioca é o principal produto derivado da mandioca para a alimentação humana no Brasil, sendo consumida e produzida em todo o País, em grande parte nas regiões Norte e Nordeste.

O padrão de qualidade desse produto ainda é uma questão em discussão, pois se observa diferenças consideráveis nas farinhas ofertadas ao mercado. Essas diferenças decorrem de vários fatores como cultivo, solo, clima, colheita, matéria-prima e outros, mas o principal fator responsável por essa elevada variabilidade de tipos de farinha é o método de processamento. Durante as etapas de prensagem e secagem, características como acidez e umidade, por exemplo, são extremamente modificadas (Silva \& Lima, 2012).

Segundo Cereda (2005), fornos muito quentes ou frios, cargas grades ou muito pequenas, prensagem mais ou menos intensiva são alguns dos fatores que podem influenciar o padrão de qualidade da farinha. Além disso, as condições higiênico-sanitárias nas casas de farinha, a fermentação da massa e o uso de corantes também estão entre os fatores que influenciam a qualidade da farinha de mandioca e, consequentemente, a sua comercialização no mercado (Silva \& Lima, 2012).

Essa ausência de uniformidade no processo de produção é uma dificuldade agravada pela inexistência, em várias regiões do Brasil, de empresas especializadas na atividade de classificação de farinha de mandioca. Uma saída para o problema seria enviar amostras para classificadoras autorizadas de outros estados.

Neste trabalho, objetivou-se analisar através do LAQ (Laboratório de Análises Químicas da Secretaria de Desenvolvimento Agrário do estado do Ceará) farinhas de mandioca de diferentes Estados do Brasil, com base nas suas características físico-químicas, visando à verificação da adequação do produto à legislação vigente, bem como fornecer maiores informações sobre a sua composição nutricional.

\section{MATERIAL E MÉTODOS}

As amostras de farinha de mandioca com classificação e procedência diversificada (Tabela 1), foram encaminhadas ao LAQ e analisadas quanto a sua composição físico-química seguindo as normas e métodos da Legislação Brasileira (Tabela 2). Os testes foram realizados em duplicata das amostras.

Tabela 1. Classificação e procedência das farinhas de mandioca.

\begin{tabular}{ccccc}
\hline Farinha de Mandioca & Grupı & Subgrupo & Tipo & Procedência \\
\hline FM1 & Seca & Grossa & 1 & Acre \\
FM2 & D’águ & Grossa & 1 & Amazônia
\end{tabular}




$\begin{array}{lcccc}\text { FM3 } & \text { Seca } & \text { Grossa } & 1 & \text { Amazônia } \\ \text { FM4 } & \text { D'águ } & \text { Grossa } & 1 & \text { Pará } \\ \text { FM5 } & \text { Seca } & \text { Fina } & 1 & \text { Paraná } \\ \text { FM6 } & \text { Seca } & \text { Fina } & 1 & \text { RN } \\ \text { FM7 } & \text { Seca } & \text { Grossa } & 1 & \text { Paraná } \\ \text { FM8 } & \text { Seca } & \text { Média } & 1 & \text { Paraná } \\ \text { FM9 } & \text { Seca } & \text { Média } & 1 & \text { RN } \\ \text { FM10 } & \text { Seca } & \text { Grossa } & 1 & \text { Pará } \\ \text { FM11 } & \text { Seca } & \text { Grossa } & 1 & \text { Maranhão } \\ \text { FM12 } & \text { Seca } & \text { Média } & 1 & \text { Ceará } \\ \text { FM13 } & \text { Seca } & \text { Média } & 2 & \text { Alagoas } \\ \text { FM14 } & \text { Seca } & \text { Grossa } & 1 & \text { Ceará } \\ \text { FM15 } & \text { Seca } & \text { Média } & 1 & \text { Acre } \\ \text { FM16 } & \text { Seca } & \text { Fina } & 1 & \text { Sergipe }\end{array}$

FM - Farinha de Mandioca.

Tabela 2. Parâmetros físico-químicos de acordo com a Legislação Brasileira.

\begin{tabular}{cc}
\hline Variáveis & Fina / Média / Grossa \\
\hline Umidade (\%) & $<13,0$ \\
Cinzas (\%) & $<1,4$ \\
Amido (\%) & $>86,0$ \\
Fibra bruta (\%) & $<2,3$ \\
Acidez (mL NaOH N/100g) & $<3,0$ \\
\hline FONTE: BRASIL, 1995.
\end{tabular}

FONTE: BRASIL, 1995.

A caracterização do teor de umidade das farinhas foi baseada na determinação de perda de peso do produto, submetido ao aquecimento, segundo procedimento descrito pelo INSTITUTO ADOLFO LUTZ ( 2008). 
A obtenção do percentual de cinzas das amostras baseou-se na determinação da perda de peso do material submetido à queima em temperaturas de $550^{\circ} \mathrm{C}$ (INSTITUTO ADOLFO LUTZ, 2008). A perda de peso nos fornece o teor de matéria orgânica do alimento. A determinação de cinzas permite verificar a adição de matérias inorgânicas ao alimento.

O teor de fibra bruta baseia-se na determinação do resíduo orgânico insolúvel da amostra, após uma digestão ácida e outra alcalina. As amostras foram pesadas em balança de precisão, submetidas à digestão em solução de $\mathrm{H}_{2} \mathrm{SO}_{4}$ a $1,25 \%$ p/v por 30 minutos, seguida de $\mathrm{NaOH} 1,25 \%$ p/v por mais 30 minutos, ambas em chapa aquecedora. Ao final do processo o conteúdo residual filtrado e neutro é levado à estufa a $130^{\circ} \mathrm{C}$ durante 2 horas e posteriormente ao forno mufla por 2 horas e 30 minutos (BRASIL, 1991).

Uma titulação com hidróxido de sódio. As amostras foram pesadas em balança de precisão, diluídas em água destilada, acrescentadas de indicador acido-básico fenolftaleína $1 \%$ e tituladas com hidróxido de sódio até a coloração rósea (INSTITUTO ADOLFO LUTZ, 2008).

A determinação do teor de amido baseia-se na hidrólise energética do amido. As amostras sã foram previamente moídas, para obtenção de maior superfície de contato, pesadas em balança com exatidão de $0,1 \mathrm{~g}$, na sequência procedeu-se a adição de ácido clorídrico sendo a mistura é submetida a banho-maria. Após o resfriamento foram adicionados dois clarificantes a mistura, seguido de filtração da mesma, para então ser transferida para o tubo do polarímetro a fim de ser procedida a leitura do campo rotatório $(200 \mathrm{~nm})$.

Os experimentos foram analisados seguindo delineamento inteiramente casualizado, com 5 tratamentos (variáveis), 2 repetições, sendo uma embalagem de $1 \mathrm{Kg}$ a unidade experimental para cada amostra. Em cada repetição foram retiradas as médias das duplicatas.

\section{RESULTADOS E DISCUSSÃO}

Os resultados das determinações físico-química das 16 amostras de farinha de mandioca encontram-se na Tabela 3. Todas as análises estão de acordo com o padrão estabelecido pela Legislação Brasileira (BRASIL, 1978), Portaria n ${ }^{\circ} 554$ de 30.08.1995 da Secretaria de Agricultura e Reforma Agrária (BRASIL, 1995), entretanto as amostras apresentaram valores diversificados. Os valores de classificação segundo a Legislação encontram-se na Tabela 2.

Tabela 3. Composição química das farinhas de mandioca.

\begin{tabular}{cccccc}
\hline Variáveis & Umidade & Cinzas & Amido & Fibra Bruta & Acidez \\
\hline FMS1 & 8,21 & 1,27 & 99,08 & 1,01 & 1,75 \\
FMD2 & 11,22 & 0,72 & 90.48 & 1,45 & 2,85 \\
FMS3 & 8.97 & 1,05 & 92,3 & 1,09 & 2,3 \\
FMD4 & 10,65 & 0,78 & 89,2 & 1,36 & 2,55
\end{tabular}




\begin{tabular}{llllll} 
FMS5 & 8,63 & 0,97 & 86,07 & 1,93 & 1,25 \\
FMS6 & 5,41 & 0,83 & 88,19 & 2,21 & 1,65 \\
FMS7 & 5,89 & 0,81 & 88,99 & 0,38 & 1,45 \\
FMS8 & 7,41 & 0,72 & 89,81 & 1,88 & 1,3 \\
FMS9 & 9,84 & 0,71 & 93,79 & 1,36 & 1,15 \\
FMS10 & 8,08 & 0,67 & 89,22 & 0,79 & 0,75 \\
FMS11 & 10,01 & 0,98 & 92,27 & 1,97 & 0,75 \\
FMS12 & 10,09 & 1,35 & 93,51 & 1,83 & 0,85 \\
FMS13 & 5,47 & 1,21 & 84,97 & 0,29 & 1,05 \\
FMS14 & 5,89 & 1,32 & 88,01 & 0,62 & 2,3 \\
FMS15 & 9,03 & 1,35 & 89,37 & 0,95 & 2,4 \\
FMS16 & 7,02 & 0,91 & 87.13 & 2,07 & 1,45 \\
\hline
\end{tabular}

FMS - Farinha de mandioca do grupo seca; FMD - Farinha de mandioca do grupo d'água.

Para a análise do teor de umidade o valor máximo permitido pela Legislação é de $13 \%$ e as amostra analisadas apresentaram resultados variando entre $5,41 \%$ a $11,22 \%$. Verificou-se que FMS7 e FMS14 apresentaram valores iguais, 5,59\% de umidade. O baixo teor de umidade apresentado pelas amostras FMS6, FMS7, FMS13 e FMS14 pode ser explicado pelo processo complementar de torrefação a qual a farinha é submetida, onde parte da umidade é retirada. Já as farinhas do grupo d'água apresentaram os dois maiores valores para o teor de umidade, 11,22\% e 10,65\% para as amostras FMD2 e FMD4, respectivamente. A avaliação do teor de umidade é importante para a verificação do tempo de prateleira do produto, assim valores acima de $13 \%$ de umidade, podem proporcionar crescimento microbiano e deterioração em menos tempo que o previsto.

A avaliação do teor de cinzas pode indicar possíveis fraudes, como adição de areia ou processamento inadequado, como lavagem e descascamento incompleto para obtenção de maior peso final do produto, para isso a Legislação determinou o máximo de 1,4\% de teor de cinzas para a farinha de mandioca. Os resultados variam de $0,67 \%$ a $1,35 \%$. As amostras FMD2, FMD4, FMS5, FMS6, FMS7, FMS8, FMS9, FMS10 e FMS11 mostraram valores inferiores a $1 \%$ e as farinhas FMS12 e FMS15 apresentaram o maior valor de teor, 1,35\%. Alguns fatores podem ter influenciado nesses resultados mais altos, um deles é a presença de sujidades inorgânicas, como terra e areia, proveniente do local de armazenamento da farinha.

Alguns autores afiram que o amido é o principal componente da farinha de mandioca. A Comissão Nacional de Normas para Alimentos determina que seja necessário a presença em sua composição química, de no mínimo, $70 \%$ de amido. O teor de amido nas amostras de farinhas 
variou de 84,97 a $93,79 \%$, todos os percentuais acima do valor mínimo permitido pela Legislação Brasileira. A amostra FMS13, apresentou 84,97\% de amido, estando dentro da classificação de farinha Tipo 2. Entre as farinhas D'água a amostra FMS2 apresentou um maior teor de amido quando comparada a FMS4, com percentuais de, 90,48 e 89,20\%, respectivamente.

Para a fibra bruta, a legislação brasileira estipula valor máximo de $2,3 \%$, contudo foi possível observar diferenças significativas entre os resultados obtidos. No grupo das farinhas secas, a amostra FMS6 apresentou o maior teor $(2,21 \%)$ e a farinha FMS13 o menor valor encontrado $(0,29 \%)$. As amostras do grupo D'água apresentaram variações significativas quanto ao teor de fibra, variando de 1,36 a 1,45\%. Segundo Mattos \& Martins (2000), existem três classificações para os teores de fibra: muito alto (mínimo de $7 \mathrm{~g}$ fibra/100g), alto $(4,5 \mathrm{a} 6.9 \mathrm{~g} / 100$ g) e baixo (inferior a 2,4g/100g). Portanto, pode-se considerar que as farinhas de mandioca analisadas apresentam baixo teor de fibra.

\section{CONCLUSÃO}

As variáveis analisadas neste trabalho apresentaram resultados condizentes com o estabelecido pela Legislação Brasileira, ou seja, dentro do limite permitido para que o alimento possa ser consumido com maior segurança e melhor qualidade.

Todos os fatores avaliados mostraram coerência na identificação de grupos de similaridade entre as farinhas de mandioca seca, média e d'água.

O trabalho realizado pelo LAQ (Laboratório de Análises Químicas da Secretaria do Estado do Ceará), com base nos métodos utilizados como parâmetros de controle de qualidade para esse alimento, foi de extrema importância para a validação de consumo das farinhas, que são alimentos altamente comercializados no estado.

\section{REFERÊNCIAS}

Brasil. Decreto n. 12.486, de 20 de outubro de 1978. Normas técnicas especiais relativas a alimentos e bebidas. Diário Oficial do Estado de São Paulo. São Paulo, p. 20, 21 de out. 1978.

Brasil. Portaria n. 108, de 04 de setembro de 1991. Normas gerais de amostragem para análise de rotina. Método número 11 - Fibra Bruta. Diário Oficial [República Federativa do Brasil], Brasília, p. 19813, 17 set. 1991. Seção 1.

Brasil. Portaria n. 554, de 30 de agosto de 1995. Normas de identificação, qualidade, apresentação, embalagem, armazenamento e transporte da farinha de mandioca. Diário Oficial da República Federativa do Brasil, Brasília, DF, 01 set. 1995.

Cereda, M. P. Produtos e subprodutos. In: Souza, L. S.; Farias, A. R. N.; Mattos, P. L. P.; Fukuda, W. M. G. (Ed.). Processamento e utilização da mandioca. Cruz das Almas: Embrapa Mandioca e Fruticultura Tropical, 2005. p. 17-60. 
Instituto Adolfo Lutz. Normas analíticas do Instituto Adolfo Lutz: métodos químicos e físicos para análises de alimentos. $4^{\mathrm{a}}$ ed. São Paulo, $1^{\circ} \mathrm{Ed}$. digital, 1002 p., 2008.

Silva, S. F.: A. C. Lima; Alvarez; V. S.; Lima, M. L. B. 2012. Importância da adequação à legislação para a qualidade da farinha de mandioca. Projeto de bolsa Pibic/CNPq/Embrapa Acre. 